\title{
SAÚDE E MEIO AMBIENTE NA CONTEMPORANEIDADE: O NECESSÁRIO RESGATE DO LEGADO DE FLORENCE NIGHTINGALE
}

Health and environment in contemporaneity: the essential review of florence nightingale's legacy.

Salud y medio ambiente en la contemporaneidad: el necesario rescate del legado de florence nightingale

Silviamar Camponogara'

\section{RESUMO}

As evidências de que a sociedade contemporânea vivencia uma intensa crise ambiental são cada vez mais contundentes. Na condição de sujeitos contemporâneos, sofremos o impacto de tais problemas ambientais, mas não necessariamente desenvolvemos ações de minimização do impacto ambiental. 0 texto busca problematizar a relação entre as questões ambientais e o campo da saúde, resgatando bases conceituais que possibilitem, aos profissionais de enfermagem e saúde, refletir sobre o tema e seu papel no processo de preservação ambiental, especialmente visando destacar o legado deixado por Florence Nightingale. Conclui-se que é necessária uma retomada do legado de Florence Nightingale, de forma a valorizar a dimensão ambiental como indispensável para o processo de assistência a saúde, tanto no que se refere à promoção da saúde e da qualidade de vida, como a minimização do impacto ambiental advindo do processo de trabalho em saúde. A reflexão ética e a abordagem educativa são fundamentais nesse processo.

Palavras-chave: Enfermagem. Meio ambiente. Ecologia. Trabalhadores. Ética.

\begin{abstract}
Evidences that show that the contemporary society is going through an intense environmental crisis are more and more shocking. As contemporary subjects, we suffer the impact of such environmental problems, but not necessarily do we take actions in order to minimize this environment impact. This text aims to problematize the relation between the environment issues and the area of health, reviewing conceptual bases that may make it possible for health and nursing professionals to reflect about the topic and their role in the process of environmental preservation, especially in an attempt to highlight the legacy left by Florence Nightingale. It is necessary a resumption of the legacy of Florence Nightingale in a way to qualify the environmental dimension as indispensable for the process of health assistance, not only in terms of the promotion of health and quality of life, but also to promote the minimization of the environmental impact that comes with the work in the health area. Ethical reflection and educative approach are fundamental points in this process.
\end{abstract}

Keywords: Nursing. Environment. Ecology. Workers. Ethics.

\section{Resumen}

Las evidencias de que la sociedad contemporánea vivencia una intensa crisis ambiental son cada vez más contundentes. En la condición de sujetos contemporáneos sufrimos el impacto de tales problemas ambientales, pero no necesariamente desarrollamos acciones de minimización del impacto ambiental. El texto busca problematizar la relación entre las cuestiones ambientales y el campo de la salud, rescatando bases conceptuales que posibiliten a los profesionales de enfermería y salud reflexionar sobre el tema y su papel en el proceso de preservación ambiental, especialmente destacando el legado dejado por Florence Nightingale. Es necesaria la retomada del legado de Florence Nightingale como forma de valorizar la dimensión ambiental como indispensable para el proceso de asistencia a la salud, tanto en lo que se refiere a la promoción de la salud y de la calidad de vida, como la minimización del impacto ambiental proveniente del proceso de trabajo de la salud. La reflexión ética y el abordaje educativo son fundamentales en ese proceso.

Palabras clave: Enfermería. Medio Ambiente. Ecología. Trabajadores. Ética

${ }^{1}$ Enfermeira. Doutora em Enfermagem. Professora Adjunto da Universidade Federal de Santa Maria. Membro do Grupo de Pesquisa Trabalho, Educação, Saúde e Enfermagem. Santa Maria - RS. Brasil. E-mail: silviaufsm@yahoo.com.br 
O CONTEXTO DA ATUAL PROBLEMÁTICA AMBIENTAL E SUA RELAÇÃO COM O CAMPO DA SAÚDE: UMA QUESTÃO A SER DEBATIDA

A constatação de que estamos em meio a uma intensa problemática ambiental é algo intensamente divulgado, de diversas formas. Notícias relacionadas ao aquecimento global, às possibilidades de extinção de diversas espécies animais e vegetais, ao aumento do número de eventos climáticos catastróficos, são veiculadas diariamente. A ideia de que a vida do planeta está seriamente ameaçada já faz parte do cotidiano das pessoas, impactando suas vidas.

De uma forma geral, a maior parte dos danos ambientais tem relação com as chamadas ações antropogênicas, ou seja, aquelas causadas pelo homem, como por exemplo: 0 aumento nas emissões de dióxido de carbono, causando o denominado 'efeito estufa'; o desmatamento e as queimadas; a destruição de ecossistemas. Tais fatos se interconectam a previsões, nada otimistas, sobre um cenário de mudanças climáticas que afetariam todo o planeta. Nesse sentido, segundo o IPCC (Painel Intergovernamental sobre Mudanças Climáticas França/2007), até 2100 haverá: um aumento da temperatura média global $\left(1,8\right.$ a $\left.4^{\circ} \mathrm{C}\right)$; um aumento do nível de mar; um aumento das chuvas em cerca de $20 \%$; o gelo do Pólo Norte poderá estar totalmente derretido no verão de $2100{ }^{1}$

Diante desse panorama, é inevitável nos questionarmos sobre como o Brasil seria (ou estaria sendo) afetado. As previsões indicam que os efeitos anteriormente citados trariam um impacto sobre até 42 milhões de habitantes do litoral; um aumento da temperatura média do país (alcançando $28,9^{\circ}$ ); um aumento de até $8^{\circ} \mathrm{C}$ da temperatura da Amazônia (savanização amazônica), acompanhada de redução das chuvas; 0 aumento de 'eventos extremos' no sudeste e centro-oeste do país (ondas de calor e chuvas intensas); a ocorrência de eventos El Niño mais intensos: secas no Norte e Nordeste e enchentes no Sul e Sudeste; a alteração significativa de ecossistemas como: mangue, Pantanal e Amazônia. ${ }^{1}$

Tendo em vista a complexidade, a gravidade e a amplitude desta problemática, podemos dizer que, hoje, vivemos uma crise que não é só ecológica/biológica, mas também social, econômica, política, cultural, e, isto tem influenciado a maneira como o ser humano percebe os outros, o mundo e o seu entorno. ${ }^{2}$ Da mesma forma, embora os efeitos negativos dessa problemática sejam mais sentidos nas últimas décadas, sabe-se que a questão tem raízes profundas, relacionadas ao processo histórico de dominação da natureza pelo ser humano; ao avanço econômico e uso da natureza em favor da acumulação de capital; e, contemporaneamente, ao processo de globalização. A ideia de que o progresso humano é medido por sua capacidade de dominar e submeter o mundo natural tem norteado a busca pelo progresso econômico e técnico científico, resultando em uma visão antropocêntrica: aquela em que o ser humano é considerado o centro do universo. ${ }^{3}$

Diante da constatação de que a atual problemática abarca diversos aspectos do viver humano, já se verifica um esforço em oferecer uma nova visão sobre a complexa trama ecológica que mantém a vida no planeta e dá supor te aos seus múltiplos processos: econômicos, sociais, culturais. 0 prefixo "eco" inseriu-se nas teorias e práticas do mundo atual, levando a questionamentos sobre 0 progresso e sobre a sociedade como um todo. ${ }^{2} \mathrm{Na}$ condição de seres humanos, temos nos questionado sobre o futuro do planeta. A partir disso, houve um crescimento do movimento ambientalista no mundo inteiro, e este tema passou a ser pauta de discussão de políticos e governantes. A Conferência de Estocolmo sobre Meio Ambiente Humano (Estocolmo, 1972) serviu como marco inaugural dessa discussão. A Conferência das Nações Unidas sobre o Meio Ambiente e Desenvolvimento - Rio 92 - também foi palco de intenso debate sobre o tema, buscando o compromisso de diversos países com a preservação ambiental, por meio de um documento-guia, a Agenda 21. Infelizmente, apesar desse esforço, poucos resultados são sentidos na prática, e, hoje, governantes e pesquisadores da área têm se reunido para discutir as consequências da destruição ambiental, a exemplo da Conferência Internacional sobre Aquecimento Global, realizada em Nairóbi, em 2006, e do Painel Intergovernamental sobre Mudanças Climáticas, realizado na França, em 2007.

É inegável que vivemos um tempo de crise, que atinge todas as esferas do viver humano, sobretudo do ponto de vista ético. Vivemos um momento de acelerado avanço tecnológico, sem a necessária reflexão ética sobre o mesmo, o que coloca em risco a existência do planeta. ${ }^{4}$ Esta crise ética dever ser considerada a mais profunda e radical, à qual se vinculam outras crises (política, econômica, administrativa, epistêmica), e que trata do próprio "estar juntos", dos fundamentos e condições de vida social e das possibilidades de vida individual, já que está em jogo a imagem que temos e queremos para 0 humano. ${ }^{5}$ Além disso, é importante considerarmos 0 contexto social no qual estamos imersos, vivenciando essa crise civilizatória, o qual, certamente, nos traz diversos impactos, enquanto sujeitos contemporâneos, afetando a forma como nos comportamos e agimos, inclusive, com relação ao desenvolvimento ou não de práticas de proteção ambiental.

Alguns sociólogos contemporâneos têm trabalhado com a ideia de que vivenciamos, atualmente, a chamada Modernidade Reflexiva, na qual há a constatação dos efeitos advindos do projeto moderno de desenvolvimento técnico- 
científico e econômico, impactando a sociedade, que passa a perceber as consequências danosas ao seu processo de viver. ${ }^{6}$ Esse conceito de reflexividade é central na abordagem do autor, e atinge a todas as pessoas. Contudo, é importante demarcar que, embora essa noção de reflexividade represente um impacto sobre a vida das pessoas, inclusive do ponto de vista dos problemas ambientais, isso não significa que elas façam uma reflexão sobre tais impactos e, muito menos, que desenvolvam ações direcionadas a minimização dos mesmos.

A compreensão é de que vivemos em uma Sociedade de Riscos ${ }^{6}$, que estão disseminados globalmente (riscos produzidos localmente têm um alcance global), não podem ser precisamente medidos; e atingem todas as pessoas, independentemente da classe social. A poluição do ar, os alimentos contaminados com agrotóxicos, as chuvas ácidas, são somente alguns exemplos destes riscos.

Diante do exposto, torna-se imprescindível tecer considerações acerca da interface entre problemas ambientais e problemas de saúde. Estudos recentes têm relacionado as mudanças climáticas a questões como: mortes por estresse térmico e por desastres ambientais; aumento da incidência de doenças por veiculação hídrica; emergência de doenças infecciosas; fome, desnutrição e doenças associadas; doenças mentais. ${ }^{7}$ No Brasil, alguns estudos têm buscado estabelecer uma relação entre riscos ambientais e a ocorrência ou aumento da incidência de determinadas doenças, como, por exemplo, o aumento da incidência de doenças respiratórias e cardiovasculares à poluição do ar. Também há uma gama de estudos que buscam relacionar as mudanças climáticas ao surgimento/ressurgimento de determinadas doenças transmissíveis. Contudo, a produção científica sobre o tema é escassa. ${ }^{8}$

Com base nisso, pode-se depreender que a discussão sobre esse assunto, no âmbito do setor da saúde ainda é incipiente. Na década de 90, o Ministério da Saúde envidou esforços na criação de alguns órgãos, destinados a trabalhar na gestão das águas, do ar, no controle de vetores, visando fomentar o processo de vigilância ambiental. Também nesse sentido, está ainda em fase de construção a Política Nacional de Saúde Ambiental, a qual tem o intuito de contribuir para a formulação de estratégias de atuação no setor, em articulação com o Sistema Único de Saúde. A

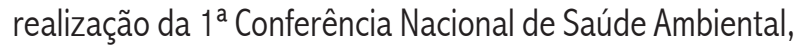
em Brasília - DF, ocorrida recentemente, em dezembro de 2009, é um exemplo concreto do quanto este debate é embrionário, tendo em vista ser o primeiro evento, organizado com o fim de discutir, coletivamente, sobre a questão.

Além disso, órgãos governamentais ligados ao Ministério do Meio Ambiente, em um primeiro momento, e ao Ministério da Saúde, por meio da Agencia Nacional de Vigilância
Sanitária, desde a década de 90, tem instituído um aporte legislativo considerável, com o propósito principal de minimizar o impacto ambiental advindo do processo de trabalho em saúde. Com isso, as instituições de saúde têm sido obrigadas a se adequar a uma série de normativas, especialmente no que tange ao gerenciamento dos resíduos sólidos dos serviços de saúde.

Esse panorama demonstra, evidentemente, que 0 debate, apesar de sua extrema relevância, ainda é muito recente, no âmbito do setor saúde. Com base nisso, é inevitável que nos questionemos sobre uma série de aspectos, dentre eles: como a problemática ambiental tem sido abordada na formação e no trabalho em saúde? Que valor tem sido atribuído pelos profissionais da saúde às questões relacionadas à problemática ambiental global? Em que medida as questões ambientais são valorizadas como determinantes do processo saúde-doença? Os trabalhadores e estudantes da área da saúde estão sendo sensibilizados/ conscientizados sobre a importância da preservação ambiental e a relação disso com o seu trabalho? Os profissionais da saúde, em seu ambiente de trabalho, agem em prol da preservação ambiental?

Dessa forma, a constatação de que vivemos uma grave crise ambiental, que nos afeta enquanto sujeitos, trazendo repercussões sobre a nossa existência atual e futura, associada a várias questões que se fazem presentes, quando pensamos na relação disso com o campo da saúde, torna um imperativo a busca de um aprofundamento do debate sobre a interface saúde e meio ambiente, no âmbito da formação profissional e do trabalho em saúde. Contudo, entendemos que esse processo não é simples, nem tampouco fácil. É algo que não pode ser simplesmente prescrito, como tarefa a ser cumprida. Ao contrário, tendo em vista sua estreita relação com questões ligadas a valores individuais, deve ter como fundamento uma profunda reflexão ética.

Diante disso, e de uma forma mais contundente, a pergunta que deve ser realizada, por cada acadêmico e trabalhador ligado à área da saúde, é: você é um cidadão e um (futuro) profissional ambientalmente correto? Evidentemente, com base nas constatações anteriores, depreendemos que, na condição de sujeitos contemporâneos, imersos em uma sociedade de riscos, somos impactados, de alguma forma, pela atual problemática ambiental. No entanto, como explica a teoria social, isso não significa que haja o desenvolvimento de ações em prol da minimização desta crise.

Sabe-se que, essa questão é bastante complexa e exige uma análise aprofundada; contudo, a proposta desse texto, é discutir sobre a relação entre atual problemática ambiental e 0 campo da saúde, resgatando bases conceituais que possibilitem, aos profissionais de enfermagem e saúde, refletir sobre o tema e sobre o seu papel no processo de preservação ambiental, especialmente visando destacar o legado deixado por Florence Nightingale. 


\section{A INTERFACE SAÚDE E MEIO AMBIENTE: DA ORIGEM DAS BASES CONCEITUAIS AO ATUAL DEBATE CIENTÍFICO}

No século XX, uma das formas de aproximação do campo da saúde com a abordagem do meio ambiente relaciona-se à concepção de qualidade de vida e promoção da saúde, que há muito integram as discussões na área, contestando os pressupostos objetivista, mecanicista, quantitativo e com ênfase na doença, que predominam em suas teorizações e práticas. Dentre esses movimentos, podemos dizer que a publicação do Informe Lalonde, no Canadá, em 1974, e a realização da Conferência Internacional sobre Atenção Primária de Saúde, em Alma Ata, em 1978, foram marcos propulsores.

Entretanto, três importantes Conferências estabeleceram as bases conceituais e políticas contemporâneas de promoção da saúde, são elas: em Ottawa (1986), em Adelaide (1988) e em Sundsval (1991). Segundo a Carta de Ottawa, a promoção da saúde é um processo, através do qual a população se capacita e busca os meios para conseguir controlar os fatores que favorecem seu bem-estar e os da comunidade, ou que a podem estar pondo em risco, tornado-a vulnerável ao adoecimento e prejudicando sua qualidade de vida. Além disso, pontua cinco áreas prioritárias de ação: elaboração de políticas públicas saudáveis; criação de ambientes favoráveis; fortalecimento da ação comunitária; desenvolvimento de habilidades pessoais e mudanças nos estilos de vida; e reorientação dos serviços de saúde. ${ }^{9}$

Com isso, além da abordagem de elementos indispensáveis à impulsão de novos pressupostos orientadores da práxis em saúde, percebemos aí a busca do estabelecimento de uma interface com a questão ambiental e a valorização da sua importância para a saúde, a partir da demarcação de uma área prioritária relacionada à criação de ambientes saudáveis.

Contudo, foi a partir da III Conferência Internacional sobre Promoção da Saúde, em Sundsvall, na Suécia, em 1991, que a questão foi demarcada, do ponto de vista da interdependência entre saúde e ambiente em todos os seus aspectos, não somente físico, mas também social, econômico, político, cultural. A criação de ambientes favoráveis à saúde implica reconhecer a complexidade das sociedades e as relações de interdependência entre diversos setores, passando pela proteção do meio ambiente e o acompanhamento do impacto que as mudanças no meio ambiente causam sobre a saúde, a ter maior ênfase na agenda da saúde..$^{10}$ Esta discussão mais acentuada sobre meio ambiente e saúde teve relação com as que precederam a realização da Conferência das Nações Unidas sobre o Meio Ambiente e Desenvolvimento - Rio 92.

Além disso, há uma vertente de discussão, que tangencia esta temática, relacionada à saúde do trabalhador. Isso se deu pelo crescimento do debate sobre a saúde do trabalhador, nas décadas de 70 e 80, a partir das investigações que relacionavam problemas ambientais com ambientes de trabalho, levando, mais tarde, a uma ampliação da discussão para a questão da produção/ambiente/saúde. ${ }^{11}$ Atualmente, 0 debate inclui também uma discussão sobre o aporte legislativo imposto às instituições, que visa assegurar a segurança do processo de trabalho em saúde e a minimização do impacto ambiental.

Contudo, os reflexos dessa discussão parecem não estar tão evidenciados na prática profissional em saúde e, particularmente, da enfermagem. Alguns desafios decorrem dessa constatação. Um deles relaciona-se a como tornar esses elementos parte da formação e do trabalho em saúde? Poderíamos de uma forma bem objetiva, nos perguntar: como, na qualidade de enfermeiros, estamos cuidando do meio ambiente? Em que medida consideramos as questões ambientais, determinantes do processo saúde-doença? Daí decorre um questionamento sobre como se dá o processo de instrumentalização de enfermeiros, equipe de enfermagem, demais trabalhadores da saúde e acadêmicos da área da saúde sobre a interface saúde e meio ambiente.

Na esteira desse processo reflexivo, apresenta-se um segundo desafio, relacionado à busca de um agir ecológico consciente no contexto do trabalho de enfermagem e da saúde. Tal desafio parte do pressuposto que uma atitude ecológica é mais do que a soma de bons comportamentos, e de que ter uma consciência ecológica pressupõe saber por que agir ou não agir, ou seja, as motivações para determinada atitude. É importante considerar também que o agir envolve a tomada de decisões e que não é algo que está apenas na esfera da racionalidade, mas envolve também sentimentos. Com base nisso, depreendemos que a construção de uma consciência ecológica por parte de profissionais de enfermagem e da saúde não é algo fácil, que possa ser prescrito, nem tampouco se restringe ao cumprimento de tarefas e normas.

A ciência desses desafios obriga-nos, enquanto profissionais, a buscar maiores subsídios para a atuação profissional, de forma a construir conhecimentos que nos possibilitem agir consciente e responsavelmente em prol da preservação ambiental e da valorização dos determinantes ambientais no processo de assistência à saúde das populações. Diante disso, a busca de referenciais que possam oferecer suporte a essa discussão é indispensável, e, neste caso, em especial, não há como não destacar o legado deixado por Florence Nightingale, com sua mensagem de valorização do ambiente como indispensável para o processo de cura das pessoas.

\section{O LEGADO DE FLORENCE NIGHTINGALE: CONTRIBUIÇÕES PARA A VALORIZAÇÃO DA INTERFACE SAÚDE E MEIO AMBIENTE}

A despeito dos avanços conceituais propostos nas discussões engendradas no campo da saúde, a respeito de novas concepções sobre promoção da saúde e qualidade de vida, o que se verifica é a permanência de uma prática em 
saúde ainda arraigada ao modelo tradicional, biomédico, que vislumbra a cura com base no tratamento de órgãos doentes, por meio da medicalização. A ideia de um olhar mais integral sobre o sujeito e o contexto onde se insere ainda parece distante no fazer em saúde. Dessa forma, enquanto trabalhadores da área da saúde, não podemos deixar de fazer referência ao legado de Florence Nightingale, a precursora da enfermagem moderna, que viveu no período de 1820 a 1910, reconhecidamente pioneira no que se refere ao pensamento filosófico, científico e ético para a enfermagem. Assim, mesmo um século depois de sua morte, o pensamento de Florence ecoa fortemente em nossa vida contemporânea e traz, apesar desses 100 anos de distância, elementos fundamentais para reflexão sobre o nosso agir profissional, particularmente no que se refere à interface saúde e meio ambiente, diante da atual problemática ecológica.

A Teoria Ambientalista proposta por Florence Nightingale tem fundamental importância para a discussão de inúmeros aspectos relacionados à nossa responsabilidade socioambiental. Por meio de seu livro 'Notas sobre Enfermagem', sua notável construção bibliográfica, suas ideias são expressas e ganharam notoriedade. Nesse sentido, para Florence, o conceito de meio ambiente é central, uma vez que afeta a vida das pessoas e é capaz de contribuir para sua saúde ou adoecimento, bem como para o processo de cura. Florence enfatiza, especialmente, aspectos relacionados ao ambiente físico, o que tem relação com o contexto em que se encontrava ao tecer suas reflexões, que envolvia o período inicial da industrialização na Inglaterra e os campos de Guerra da Crimeia, onde as péssimas condições de saneamento ambiental e a promiscuidade em que se encontravam os pacientes nos hospitais, resultavam em altas taxas de mortalidade, exigindo atenção imediata e constante. $^{12}$

Segundo Florence, alguns elementos têm particular importância para a manutenção de um ambiente saudável, no sentido de facilitar o processo de cura e o viver saudável. Dentre eles podemos destacar: a ventilação, com relação à provisão de ar fresco e puro; a iluminação, envolvendo a claridade e a luz solar direta; o calor, especialmente relacionado a evitar o resfriamento dos pacientes; a limpeza, fazendo referência já à prevenção de infecções; os ruídos, enfatizando a necessidade de manter-se silêncio; os odores e a alimentação. $^{12}$

Dessa forma, segundo Florence, o conceito de ambiente engloba diversos elementos que podem contribuir para o processo de recuperação. Apesar de enfatizar os aspectos envolvidos do ambiente físico, a autora também faz referência ao ambiente psicológico e ao social. Menciona a importância do desenvolvimento de atividades que mantenham a mente estimulada, enfatizando a necessidade de comunicação com o paciente e a necessidade de coleta de dados relativos à vida social do paciente, o que deve ser objeto de atenção da enfermagem. ${ }^{13}$
Ao demarcar que a enfermagem deveria atuar tanto em nível preventivo como de reabilitação, Florence destaca a sua contribuição para o processo restaurador ao colocar o paciente em condições para que a natureza possa agir sobre ele, por meio da promoção de um ambiente no qual possa cuidar-se e ser cuidado pelos outros. Assim, o principal papel da enfermeira seria o de ajudar o doente a manter suas forças vitais, a fim de prevenir a doença, resistir a ela ou recuperar-se dela, utilizando-se dos recursos da natureza. Alerta que o foco, para tanto, deve estar na pessoa como um todo e não apenas em um órgão doente. ${ }^{12}$

Em geral, o legado de Florence aponta que a saúde é resultante da interação de fatores ambientais, evidenciando, com primazia, a necessidade de considerá-los como indispensáveis na abordagem do processo saúde-doença. Contudo, apesar do legado de Florence e do debate sobre a importância dos fatores ambientais para a promoção da saúde e qualidade de vida, já iniciado no campo da saúde, a realidade nos aponta para um cenário em que estes aspectos ainda não são, plenamente, considerados no processo de trabalho em saúde.

Estudo de campo realizado recentemente, com trabalhadores hospitalares, revela que, é muito presente, entre os sujeitos, uma visão naturalizada do meio ambiente, entendido como ambiente natural, externo ao contexto de ação em saúde, especialmente no processo laboral. Indubitavelmente, esta concepção tem vinculação com o fato de nos desenvolvermos orientados por uma concepção fundamentada na dualidade ser humano-natureza, assim como na manutenção de um ideário de natureza como ordem biológica. Isso se torna ainda mais evidente no contexto do trabalho hospitalar, o qual é, historicamente, concebido como local de isolamento e segregação, onde a racionalidade biomédica está for temente arraigada. ${ }^{14}$

Em geral, no contexto do trabalho hospitalar, há, entre os trabalhadores, uma visão de separação entre processo saúde-doença, hospital e meio ambiente, mesmo quando tencionados a refletir sobre a atual problemática ecológica, ou, quando muito, fazem algum tipo de conexão com as normatizações sobre o processo de gerenciamento dos resíduos sólidos dos serviços de saúde, demonstrando maior preocupação com o lixo contaminado. Isso tem relação com a falta de um processo reflexivo sobre o tema, com os processos de subjetivação típicos do setor, com o estilo gerencial burocratizado predominante em instituições hospitalares, bem como com um processo de trabalho prescritivo, orientado por tarefas. $^{14}$

A busca de uma concepção de interação entre ser humano e meio ambiente parece ser algo ainda bastante distante, carecendo de um sólido processo reflexivo sobre a prática profissional em saúde. Nesse sentido, o meio ambiente não pode ser visto apenas como sinônimo de natureza intocada, mas como um campo de interações entre cultura, sociedade e 
processos biológicos. Precisa ser visto como um espaço relacional, em que o ser humano, longe de ser visto apenas como uma presença perturbadora, seja um agente pertencente a teia de relações. ${ }^{3}$

Dessa forma, percebe-se que, embora a precursora da Enfermagem Moderna tenha deixado entre seus ensinamentos o de que o ambiente é parte essencial do processo saúde-doença, isso ainda não é plenamente observado por alguns profissionais. Acreditamos que esse fato ganhe ainda mais relevância, ao considerarmos o atual contexto social em que estamos imersos: o da sociedade de riscos, em que os problemas ambientais se fazem sentir no cotidiano dos sujeitos, afetando de diferentes maneiras o seu processo de viver. Contudo, a despeito dessa constatação, a questão que se coloca para reflexão é que, justamente, não há um processo reflexivo sobre a temática, o que leva os sujeitos a agirem automaticamente, quando muito, orientados por normas e rotinas.

Da mesma maneira, a valorização das condições ambientais como determinantes do processo saúde, já preconizadas por Florence e proclamadas nos diversos eventos que apontaram as premissas para uma nova concepção de promoção da saúde e da qualidade de vida, com base em nossa experiência empírica e nas escassas produções científicas sobre o assunto, ainda não se faz sentir no cotidiano do trabalho em saúde e enfermagem. A predominância do modelo biomédico, que busca causas lógicas para efeitos orgânicos, em um corpo doente, refém da medicalização e do arsenal tecnológico que reveste, particularmente, a atenção hospitalar a saúde, impede que o trabalhador, inclusive da enfermagem, amplie seu espectro de ação, resultando na reprodução de um modelo contrário aos ensinamentos de Florence.

Outro motivo relacionado a essa forma de agir tão arraigada ao trabalho em saúde tem relação com a ignorância sobre as determinações ambientais e suas implicações sobre o processo saúde-doença e para o trabalho em saúde. A falta de conhecimentos sobre as questões ambientais tem sido apontadas como geradoras de grande lacuna no que se refere ao desenvolvimento de ações de preservação ambiental, por parte de trabalhadores hospitalares. ${ }^{14}$ Pode-se dizer que, quanto mais conhecimento científico tivermos a cerca dos determinantes ambientais e dos impactos advindos do processo laboral em saúde sobre o meio ambiente, melhores condições teremos de tomar decisões e agir responsavelmente, na qualidade de enfermeiros e trabalhadores da saúde.

Com base nisso, podemos depreender que, assim como a enfermagem se tornou um projeto de vida para Florence Nightingale, o trabalho, particularmente orientado pela valorização do ambiente, deve ser um valor essencial para cada trabalhador. Desta forma, acreditamos que seja possível uma atuação consciente e responsável, no sentido de minimizar impactos ambientais provocados pelo processo de assistência à saúde e em prol da promoção da saúde das pessoas.
Para tanto, faz-se necessário que cada profissional, possa, por meio de um sólido processo reflexivo, perceber-se como ator social, adquirindo a consciência ambiental que the permita um agir responsável e ambientalmente correto. Este processo é fundamental, correndo-se o risco, caso contrário, de que a questão da responsabilidade com a preservação ambiental, não ultrapasse o status de um discurso banalizado. Há estreita vinculação entre moral e emoção, ou seja, para que algo seja considerado um dever, deve afetar o indivíduo de modo a motivar sua vontade, o que só é possível com a participação da emoção, que está na essência de nossa moral. Assim, surge o sentimento de responsabilidade, vinculado a uma ética que tem um lado objetivo, ligado à razão, e a um lado subjetivo, ligado ao sentimento, sendo ambos complementares. ${ }^{4}$

A consecução de qualquer meta de mobilização social, em prol da preservação ambiental, deve estar ancorada em três esferas da vida social: a da subjetividade individual, ou seja, na forma de pensar e sentir; a microssocial, aderente ao relacionamento interpessoal e práticas cotidianas; e a esfera da ação pública. ${ }^{15} \quad$ Com base nisso, subtende-se que a reflexão ética e a educação são a base do processo de conscientização, a qual pressupõem uma reflexão crítica sobre nossos desejos, motivações, aspirações e condutas.

A ampliação do debate sobre a problemática ambiental e o trabalho em saúde e a retomada dos pressupostos já defendidos por Florence, há mais de um século, deve incluir a solidificação dessa discussão, no âmbito da formação profissional, da educação em serviço (por meio da educação permanente) e da educação em saúde. A valorização do meio ambiente, como força capaz de promover e recuperar a saúde das pessoas e populações deve estar presente no cotidiano, nos diversos cenários onde se dão o ensino e a prática assistencial em saúde. Da mesma forma, a constatação de que, por meio dos diversos processos que compõem as práticas de saúde, podemos afetar o meio ambiente deve estar introjetada entre os trabalhadores, como passo inicial para a aquisição valores que conduzam a formação de uma consciência ambiental.

\section{ALGUMAS CONSIDERAÇÕES}

Com base no exposto, depreende-se que a retomada do importante legado deixado por Florence Nightingale é fundamental. Inevitavelmente, isso significa admitir que a busca da ampliação da consciência/responsabilidade ambiental no contexto do trabalho em saúde pressupõe compreender que a problemática ambiental é um evento complexo, socialmente construído, que exige esforços individuais e coletivos para sua resolubilidade, tendo importante impacto sobre o processo saúde-doença.

Diante disso, a obtenção e a construção de conhecimentos sobre o tema, bem como a realização de reflexão ética sobre 0 assunto, são fundamentais para a efetiva 
incorporação da interface saúde e meio ambiente no trabalho em saúde, com vistas à busca da promoção da saúde e de melhor qualidade de vida, à otimização do processo de cura e reabilitação e à minimização do impacto ambiental advindo do processo de trabalho em saúde.

Para tanto, há que se pensar em (re)discutir o conceito de meio ambiente, no sentido de incorporar diferentes perspectivas a ele associadas (social, econômica, cultural, dentre outras), ainda hoje negligenciadas em favor de um olhar restrito ao aspecto biológico. Da mesma forma, precisamos pensar em olhar os sujeitos, que são nosso objeto de trabalho (pessoas, famílias, comunidades), de uma forma mais abrangente, integral, menos medicalizada e biologicista, de forma a valorizá-los enquanto seres humanos, inseridos em um contexto que integra o social e o natural, que os influencia e é, por eles, influenciado.

Finalmente, é preciso acreditar que, enquanto trabalhadores da saúde, podemos (e devemos), nos basear em nossos valores e crenças, tomar decisões conscientes e agir responsavelmente com o meio ambiente, já que somos todos atores sociais, responsáveis pelos nossos atos imediatos e futuros. Para isso, precisamos rumar em busca de uma ética ecocêntrica, que estabeleça uma relação de horizontalidade entre os seres humanos e os demais elementos do ambiente, como já preconizava Florence Nightingale, há mais de um século.
9-Buss PM. Uma introdução ao conceito de promoção da saúde. In: Czeresnia D; Freitas CM, organizadores Promoção da saúde: conceitos, reflexões, tendências. Rio de Janeiro: Ed Fiocruz; 2003. p. 15-38.

10-Buss PM. Promoção da saúde e qualidade de vida. Cienc Saude Colet. 2000; 5(2):163-177.

11- Tambellini AMT, Câmara VM. A temática saúde e ambiente no processo de desenvolvimento do campo da saúde coletiva: aspectos históricos, conceituais e metodológicos. Cienc Saude Colet. 1998; 3(2): 47-59.

12-Nightingale F. Notas sobre enfermagem. São Paulo: Cortez; 1989.

13-George JB, et al. Teorias de enfermagem: os fundamentos para a prática profissional. Porto Alegre: Artes Médicas; 1993. p.38-48.

14-Camponogara S Um estudo de caso sobre a reflexividade ecológica de trabalhadores hospitalares [tese]. Florianópolis: Programa de PósGraduação em Enfermagem, Universidade Federal de Santa Catarina; 2008.

15-Pelicioni AF. Ambientalismo e educação ambiental: dos discursos às práticas sociais. Mundo Saúde. 2006 out/dez; 30(4): 532-43.

\section{REFERÊNCIAS}

1-Leite M. Um novo clima no Brasil. Cienc Amb. 2007 jan-jun; 10(34): 05-9.

2-LeffE. Saber ambiental: sustentabilidade, racionalidade, complexidade, poder. Petrópolis(RJ): Vozes; 2001.

3-Carvalho ICM. Educação ambiental: a formação do sujeito ecológico. São Paulo: Cortez; 2004.

4-Jonas H. El principio de responsabilidad: ensayo de una ética para la civilización tecnológica. Barcelona: Ed Herder; 1995.

5-Schramm FR. A terceira margem da saúde: ética natural, complexidade, crise e responsabilidade no saber-fazer sanitário. Brasília(DF): UNB; 1996.

6-Guiddens A. A vida em uma sociedade pós-tradicional. In: Beck U, Giddens A, Lash S. Modernização reflexiva: política, tradição e estética na ordem social moderna. São Paulo: Ed Unesp; 1997. 73-134.

7-Barcellos A, Monteiro AMV, Corvalán C, Carvalho MS, Artaxo P, Hacon S, et al. Mudanças climáticas e ambientais e as doenças infecciosas: cenários e incertezas para o Brasil. Epidemiol Serv Saúde. 2009 jul-set; 18(3): 201-04.

8-Camponogara S, Kirchhof ALC, Ramos FRS. Uma revisão sistemática sobre a produção científica com ênfase na saúde e meio ambiente. Cienc Saude Colet. 2008; 13(2): 427-39. 